\title{
Esophagus and Esophagogastric Junction Cancer pT4 TNM Finding v7
}

National Cancer Institute

\section{Source}

National Cancer Institute. Esophagus and Esophagogastric Junction Cancer pT 4 TNM

Finding V7. NCI Thesaurus. Code C89734.

Esophagus and esophagogastric junction cancer with tumor invading adjacent

structures. (from AJCC 7th Ed.) 